\title{
O ativismo judicial na visão de Ronald Dworkin
}

\author{
Eduardo Fernando Appio \\ Universidade Federal do Paraná, Curitiba/PR, Brasil.E-mail: eduardoappio@yahoo.com.br
}

\section{Resumo}

O presente texto busca questionar a alegada correspondência entre as proposições doutrinárias (e judiciais) que defendem o ativismo judicial no Brasil e algumas das ideias de Ronald Dworkin, as quais, involuntariamente, acabaram servindo para incrementar os equívocos que hoje se cometem, com especial enfoque no controle judicial de políticas públicas. Com a Constituição Federal de 1988, muitos autores viram a oportunidade de se aproximar de países com instituições e tradição jurídica já consolidadas, tendo proliferado o número de teses e estudos que encontravam no direito alemão ou norte-americano o fundamento de legitimidade para as pouco modestas aspirações históricas ao final do século XX. Passados trinta anos da promulgação da Constituição, fica evidente que o cenário é totalmente distinto do originalmente concebido. Entre a força normativa da Constituição e o jogo de forças sociais e grupos de interesse que gravitam no país, fica a desagradável impressão de que a Constituição pode ser mudada segundo a conveniência dos grupos econômicos, ainda que à custa dos direitos sociais. Neste novo contexto, alguns segmentos da comunidade jurídica se viram mergulhados em intensos debates de índole essencialmente política, tratando de temas até então considerados como tabus pela interpretação que o Supremo Tribunal Federal (STF) conferia ao princípio da separação dos Poderes. O estudo conclui que o tipo de ativismo judicial praticado hoje, em larga escala, no Brasil, não encontra nenhum amparo (ainda que remoto) na vasta obra de Ronald Dworkin, porque se busca sua fonte de legitimidade em um patológico voluntarismo judicial que, historicamente, apenas serviu de fonte de legitimação para regimes totalitários.

Palavras-chave

Ativismo judicial; Ronald Dworkin; Constituição Federal de 1988.

\section{Judicial activism in Ronald Dworkin's view}

\author{
Abstract

The present article aims to question the alleged correspondence between the doctrinal (and judicial) propositions that defend judicial activism in Brazil and some of Ronald Dworkin's ideas, which, involuntarily, served to increase the misunderstandings that are being made today, with special focus in judicial control of public policies. With the Federal Constitution of 1988, many authors saw the opportunity to get closer of countries with already established legal institutions and traditions, and the number of theses and studies that 
found in German or American law the foundation of legitimacy for the not very modest aspirations at the end of the 20th century. Thirty years after the promulgation of the Constitution, it is evident that the scenario is totally different from the one originally conceived. Between the normative force of the Constitution and the set of social forces and interest groups that gravitate in the country, there is the unpleasant impression that the Constitution can be changed according to the convenience of economic groups, albeit at the expense of social rights. In this new context, some segments of the juridical community were immersed in intense debates of an essentially political nature, dealing with themes that had been considered as taboos by the interpretation that the Federal Supreme Court (STF) conferred on the principle of separation of powers. The study concludes that the type of judicial activism practiced today, in a large scale, in Brazil, finds no (although remote) support in Ronald Dworkin's vast work, because its source of legitimacy is sought in a pathological judicial voluntarism that, historically, served only as a source of legitimation for totalitarian regimes.

Keywords

Judicial activism; Ronald Dworkin; Federal Constitution of 1988.

\section{Sumário}

Introdução; 1. O que é ativismo judicial?; 2. Direito como integridade; Conclusão; Referências.

\section{Introdução}

A doutrina jurídica brasileira tem se aproximado, não sem tardar, da experiência anglo-americana do direito e desta fascinante aventura que representa uma Constituição escrita com força vinculante ${ }^{1}$. No afã de alcançar uma maior efetividade do texto constitucional brasileiro, alguns autores foram tentados a buscar nos livros e na visão do jusfilósofo norte-americano Ronald Dworkin a justificativa e o argumento de autoridade para algumas de suas proposições através das quais defendem o ativismo dos juízes. É inegável que temos todos um objetivo comum, dentro do direito constitucional, qual seja, ampliar o alcance e o vigor das disposições da Constituição Federal de 1988, com especial ênfase nos chamados direitos sociais.

Os autores que se dedicaram ao estudo do direito constitucional - e, especialmente, do direito constitucional comparado - sentem-se impulsionados a acreditar que a simples existência de um texto normativo é capaz de mudar tradições jurídicas e a mentalidade de nossos operadores.

Através desta janela emancipatória que significou a Constituição Federal de 1988, muitos de nós vimos a singular oportunidade de nos aproximar de países com instituições e tradição jurídica já consolidada, tendo proliferado o número de teses e estudos que encontravam no direito

${ }^{1}$ MARINONI, Luiz Guilherme. Precedentes Obrigatórios. São Paulo: RT, 2010. 
alemão ou norte-americano o fundamento de legitimidade para as pouco modestas aspirações históricas ao final do século XX.

Passados agora trinta anos da promulgação de nossa Constituição Federal, fica evidente que o cenário é totalmente distinto do originalmente concebido. Entre a força normativa da Constituição e o jogo de forças sociais e grupos de interesse que gravitam no país, fica a desagradável impressão de que a Constituição pode ser mudada segundo a conveniência dos grupos econômicos, ainda que à custa dos direitos sociais. Neste novo contexto, alguns segmentos da comunidade jurídica - especialmente os juízes - se viram mergulhados em intensos e apaixonados debates de índole essencialmente política, tratando de temas até então considerados como tabus pela interpretação que nosso Supremo Tribunal Federal (STF) conferia ao princípio da separação dos Poderes².

Não sem razão vemos o avanço gradual de um movimento que hoje se revela sólido rumo ao ativismo judicial, o que para os críticos representa uma expressão eufemística de simples populismo judiciário latino-americano; e, para seus apoiadores, apresenta-se como única alternativa ante a uma erosão histórica dos Poderes Legislativo e Executivo no Brasil.

O presente texto busca questionar a alegada correspondência entre as proposições doutrinárias (e judiciais) que defendem o ativismo judicial no Brasil e algumas das ideias de um brilhante autor norte-americano que, involuntariamente, acabaram servindo para incrementar os equívocos que hoje se cometem, com especial enfoque no controle judicial de políticas públicas ${ }^{3}$.

\section{O que é ativismo judicial?}

O ativismo judicial tem sido considerado como uma marcante característica do Judiciário contemporâneo, que o distingue das funções até então desempenhadas e que, em linhas gerais, resumiam-se a revisar, retrospectivamente, fatos e atos jurídicos do passado remoto. O Poder Judiciário não sofria a força e a ingerência direta do clamor popular quando da decisão. A própria cobertura que os meios de comunicação faziam do trabalho do poder judiciário era superficial e distanciada.

2 Art. 2o "São Poderes da União, independentes e harmônicos entre si, o Legislativo, o Executivo e o Judiciário".

${ }^{3}$ Este tema foi totalmente reformulado, ao longo dos últimos anos, pela jurisprudência do Supremo Tribunal Federal do Brasil que, atualmente, aceita com tranquilidade a intervenção do Poder Judiciário na determinação do conteúdo concreto de tarefas a serem desempenhadas no âmbito interno dos demais Poderes da República. Veja-se, por exemplo, o seguinte julgado: "É lícito ao Judiciário impor à Administração Pública obrigação de fazer, consistente na promoção de medidas ou na execução de obras emergenciais em estabelecimentos prisionais. Supremacia da dignidade da pessoa humana que legitima a intervenção judicial" (RE 592.581, rel. min. Ricardo Lewandowski, j. 13-8-2015, P, DJE de 10-2-2016, tema 220). 
Neste sentido, os juízes de hoje (inclusive no Supremo Tribunal Federal) reduziram, de forma significativa, o espaço até então reservado para as questões ditas nitidamente políticas (doutrina das political questions) para avançar - inclusive de forma prospectiva - em toda e qualquer questão que envolva o texto constitucional.

O termo ativismo judicial, inclusive, tem sido utilizado pela doutrina de maneira francamente pejorativa, com o sentido de criticar aquelas decisões representativas de grandes mudanças para o país - como, por exemplo, no caso do casamento entre pessoas de mesmo sexo no Brasil - e que possuem um grande déficit de participação popular na sua elaboração, sendo tidas por muitos como notoriamente ilegítimas dentro de uma tradicional democracia ${ }^{4}$. 0 ativismo judicial, segundo esta corrente que o repele, carrega em si "uma crítica às decisões das Cortes que vão além de suas prerrogativas originais" ${ }^{5}$.

O resultado deste movimento histórico foi a proliferação de um grande número de ações com conteúdo claramente constitucional - muitas das quais ações coletivas promovidas pelos Ministérios Públicos -, as quais demandavam junto aos demais poderes a adoção de medidas concretas (normativas e/ou executivas) visando garantir a efetividade dos chamados direitos sociais ${ }^{6}$.

O Supremo Tribunal Federal (STF) brasileiro tem prontamente atendido a este tipo de demandas, não somente ao aceitar a legitimidade ativa do Ministério Público para a propositura de ações coletivas que envolvam o controle judicial de políticas públicas, como também ao emitir ordens judiciais concretas destinadas ao Poder Executivo para a sua efetiva implementação?.

\footnotetext{
${ }^{4}$ No livro Direito das minorias defendi uma concepção segundo a qual nosso Supremo Tribunal Federal (STF) acertou ao derrubar toda e qualquer limitação ao casamento entre pessoas de mesmo sexo. Hoje, todavia, revendo o tema, confesso que esta concepção está profundamente equivocada, na medida em que a Constituição de 1988 regulou, expressamente, a matéria prevendo a união entre homem e mulher, deixando pouco (ou mesmo nenhum) espaço para a interpretação (criação judicial). O ativismo judicial, ainda que bemintencionada, não pode servir de autorização ampla para que o Supremo Tribunal ou qualquer juiz modifique o texto expresso da Carta de 1988. A razão estava, na época, com Lenio Streck, o qual muito embora defenda este tipo de casamento (como eu também), advogava a tese de que esta alteração da Carta de 1988 deveria ter sido feita através de Emenda à Constituição e não através de uma simples decisão do Supremo Tribunal, sequer precedida de audiências públicas.

5 DICKSON, Brice. Judicial activism in common law Supreme Courts. New York: Oxford University Press, 2007 p. 70

${ }^{6}$ Art. 6o "São direitos sociais a educação, a saúde, a alimentação, o trabalho, a moradia, o transporte, o lazer, a segurança, a previdência social, a proteção à maternidade e à infância, a assistência aos desamparados, na forma desta Constituição". (Redação da EC 90/2015)

7 "O direito a segurança é prerrogativa constitucional indisponível, garantido mediante a implementação de políticas públicas, impondo ao Estado a obrigação de criar condições objetivas que possibilitem o efetivo acesso a tal serviço. É possível ao Poder Judiciário determinar a implementação pelo Estado, quando inadimplente, de políticas públicas constitucionalmente previstas, sem que haja ingerência em questão que envolve o poder discricionário do Poder Executivo". (RE 559.646 AgR, rel. min. Ellen Gracie, j. 7-6-2011, 2a T, DJE de 24-6-2011. No mesmo sentido, v. ARE 654.823 AgR, rel. min. Dias Toffoli, j. 12-11-2013, 1a T, DJE de 5-12-2013).
}

\section{Revista Publicum}

Rio de Janeiro, v. 4, n. 2, 2018, p. 37-53

http://www.e-publicacoes.uerj.br/index.php/publicum

DOI: $10.12957 /$ publicum.2018.37953 
O espaço demarcado às questões tidas como essencialmente políticas acabou sendo completamente eliminado pelo Supremo Tribunal Federal ao longo dos últimos anos, de maneira que resulta muito difícil se imaginar uma hipótese em que o Judiciário exerça, hoje, efetiva autocontenção ou deferência judicial em favor dos demais Poderes.

Ainda que, do ponto de vista histórico, a tradição brasileira que remonta às Cartas de 1934 e 1937, tenha estimulado a previsão expressa das matérias tidas como exclusivamente políticas (e, portanto, infensas ao reexame judicial), as Constituições posteriores deixaram um imenso espaço aberto para a interpretação judicial.

A abertura interpretativa é de todo saudável, na medida que ao invés de interditar, previamente, a jurisdição das Cortes - especialmente do Supremo Tribunal Federal - em relação a determinados temas sensíveis, compete ao próprio Poder Judiciário fixar a latitude e longitude de sua própria jurisdição. Esta atribuição, inclusive, também é uma atividade essencialmente política e depende, por óbvio, da conjuntura social e econômica do país, muito embora não seja recomendável que a Corte se afaste por completo de seus próprios precedentes sobre o assunto, em nome da segurança jurídica.

O termo ativismo judicial - ou, ainda, ativismo judiciário - encontra no Brasil, por conseguinte, uma concepção totalmente distinta da existente na Inglaterra e nos Estados Unidos, locus a partir do qual escreve Ronald Dworkin.

No Brasil, o ativismo judicial está intimamente vinculado a um objetivo claramente demarcado pelos próprios juízes, qual seja o de garantir concretude aos chamados direitos sociais ante à natural escassez de recursos financeiros.

O judiciário busca examinar os próprios critérios intrínsecos adotados pelos chamados ramos eleitos pela população (Legislativo e Executivo) quando da alocação dos recursos públicos interferindo, por vezes, na própria Lei Orçamentária anual e também no plano plurianual votados pelo Congresso.

No caso dos Estados Unidos, importante que se registre, desde logo, que segundo interpretação conferida pela própria Suprema Corte (U.S. Supreme Court), não existem direitos sociais previstos pela Constituição e, portanto, não se revela legítima qualquer intervenção judicial no sentido de ordenar aos demais poderes a sua efetiva implementação.

Ainda que se revelem como fascinantes as raras decisões judiciais norte-americanas que, sob o argumento de proteger direitos individuais, ordenaram ao Poder Executivo a adoção de providências concretas, é consenso que em sede de direitos sociais a Suprema Corte irá sempre optar pela modéstia e autocontenção8.

${ }^{8}$ Após a publicação da decisão histórica de 1954 no caso Brown v. Board of Education, a U.S. Supreme Court ainda teve de adotar uma série de novas decisões concretas no sentido de implementar, efetivamente, as 
Transfere-se, pois, aos demais Poderes da República, a responsabilidade histórica e política de resolver de que maneira a riqueza coletiva do país será distribuída dentro de suas comunidades, existindo um grande apreço pela tutela da cláusula do devido processo legal (que, por sua vez, protege a vida, a liberdade e a propriedade).

Ora, se nos Estados Unidos os chamados welfare rights (ou mesmo social rights) não encontram previsão expressa na Constituição (sintética) daquele país e se a jurisprudência da Suprema Corte está fortemente consolidada em rejeitar qualquer forma - ainda que remota - de ativismo judicial nesta seara, revela-se por demais difícil trazer a voz de Ronald Dworkin em favor deste modelo de ativismo judicial que se pretende hoje no Brasil.

Não deixa de surpreender o fato de que alguns membros do nosso Supremo Tribunal Federal se sentem inequivocamente lisonjeados quando chamados de ativistas, algo que seria visto quase como uma agressão e um verdadeiro atentado à Corte em outros países.

A preocupação determinante da intervenção dos juízes da Suprema Corte dos Estados Unidos e também a razão fundante de sua legitimidade é a tutela dos chamados direitos individuais, com especial apreço às cláusulas do devido processo legal e da igualdade de tratamento. No Brasil, contrariamente, a atuação mais destacada de nossa Suprema Corte em sede de controle de constitucionalidade está firmemente atrelada à tutela dos direitos sociais, sendo certo que não raras vozes se arriscam hoje a confessar que nosso Supremo Tribunal é o mais ativista do mundo ${ }^{9}$.

Afastado o exagero desta concepção - até porque existem países com forte tradição ativista no Judiciário, como por exemplo a Colômbia e a Índia, o fato é que existem diferenças bastante significativas entre o judicial review feito pela US Supreme Court e o realizado pelo nosso Supremo Tribunal.

medidas que punham fim à segregação racial nas escolas públicas estaduais. Alguns estados do sul, com forte passado escravagista, resistiram bastante à implementação das medidas determinadas pela Suprema Corte dos Estados Unidos, ainda que a decisão de 1954 não tenha, de início, fixado um prazo final e determinante para sua realização prática (já com a intenção de evitar graves conflitos sociais).

9 Importante registrar um dos marcos históricos desta transformação na jurisprudência de nosso Supremo Tribunal, que, até então tinha uma postura considerada por muitos como excessivamente tímida na concretização dos direitos sociais: a ADPF 45, de relatoria do Ministro Celso de Mello, Ministro que mudou, significativamente, no curso dos anos, a sua interpretação acerca dos limites possíveis à intervenção judicial: "ARGÜIÇÃO DE DESCUMPRIMENTO DE PRECEITO FUNDAMENTAL. A QUESTÃO DA LEGITIMIDADE CONSTITUCIONAL DO CONTROLE E DA INTERVENÇÃO DO PODER JUDICIÁRIO EM TEMA DE IMPLEMENTAÇÃO DE POLÍTICAS PÚBLICAS, QUANDO CONFIGURADA HIPÓTESE DE ABUSIVIDADE GOVERNAMENTAL. DIMENSÃO POLÍTICA DA JURISDIÇÃO CONSTITUCIONAL ATRIBUÍDA AO SUPREMO TRIBUNAL FEDERAL. INOPONIBILIDADE DO ARBÍTRIO ESTATAL À EFETIVAÇÃO DOS DIREITOS SOCIAIS, ECONÔMICOS E CULTURAIS. CARÁTER RELATIVO DA LIBERDADE DE CONFORMAÇÃO DO LEGISLADOR. CONSIDERAÇÕES EM TORNO DA CLÁUSULA DA "RESERVA DO POSSÍVEL". NECESSIDADE DE PRESERVAÇÃO, EM FAVOR DOS INDIVÍDUOS, DA INTEGRIDADE E DA INTANGIBILIDADE DO NÚCLEO CONSUBSTANCIADOR DO "MÍNIMO EXISTENCIAL". VIABILIDADE INSTRUMENTAL DA ARGÜIÇÃO DE DESCUMPRIMENTO NO PROCESSO DE CONCRETIZAÇÃO DAS LIBERDADES POSITIVAS (DIREITOS CONSTITUCIONAIS DE SEGUNDA GERAÇÃO)". (Decisão publicada no DJU de 4.5.2004). 
Este dado sugere, pelo menos, alguma cautela ao importarmos decisões e doutrinadores dos Estados Unidos em favor de posições tidas como progressistas dentro do nosso Poder Judiciário; ainda que se reconheça aquele país como a pátria gestora do constitucionalismo (escrito) e dotada de um Judiciário de excelente nível.

Estabelecidas estas premissas que considero como fundamentais e sem as quais se pode, facilmente, incorrer no erro de invocar precedentes e doutrinas que envolvam direitos individuais como uma justificativa para o ativismo judicial em sede de direitos sociais (e coletivos) - já podemos, agora, buscar os pontos de aproximação com a doutrina de Ronald Dworkin, pontuando de que maneira seus ensinamentos podem nos ser úteis aqui no Brasil. Registre-se, contudo, que o autor não pretendia escrever com o objetivo de solucionar problemas no estrangeiro, mas, sim, descrever a prática jurídica dos Estados Unidos (e, eventualmente, da Inglaterra).

Portanto, quando se fala em ativismo judicial no Brasil, devemos ter em mente que estamos tratando de concretização judicial de direitos sociais frente à alegação de escassez de recursos financeiros ou mesmo do respeito à discricionariedade política dos chamados ramos eleitos pela população.

Contrariamente, quando estivermos versando sobre o ativismo judicial nos Estados Unidos, estaremos falando de um conteúdo muito diverso, qual seja a tutela judicial de direitos individuais frente à alegada indevida intervenção do Estado (ou dos estados-membros) na esfera de liberdade do cidadão. O direito norte-americano aceita com grandes restrições os conceitos de direitos econômicos e sociais, ao contrário do que sucede, por exemplo, na Alemanha ${ }^{10}$.

A preocupação central é com o conceito de liberdade, ainda que esteja atrelado aos conceitos de igualdade de tratamento (equal treatment) e tratamento como um igual (treatment as equal) ${ }^{11}$.

No Brasil, a preocupação central da jurisprudência é com a correta alocação dos bens sociais a partir da leitura possível de uma Constituição que assume como uma de suas principais

10 TUSHNET, Mark. Weak Courts, strong rights: judicial review and social welfare rights in comparative constitutional law. New Jersey: Princeton University Press, 2008, p. 198

${ }^{11}$ Esta distinção, inclusive, é de seminal importância na obra de Ronald Dworkin, na medida em que ele defende o que pode ser reputado como um conceito ampliado da liberdade (ele chama de concepção liberal da igualdade). Segundo Ronald Dworkin “(...) todo cidadão governado pela concepção liberal de igualdade tem um direito a igual consideração e respeito. Existem, no entanto, dois direitos distintos que podem estar compreendidos neste direito abstrato. $O$ primeiro deles é o direito a igual tratamento (equal treatment), isto é, a mesma distribuição de bens e oportunidades que qualquer outra pessoa possua ou receba. (...) [O] segundo é o direito a ser tratado como igual (treatment as an equal). Este é o direito, não a uma distribuição igual de algum bem ou oportunidade, mas o direito a igual consideração e respeito na decisão política sobre como tais bens e oportunidades serão distribuídos". DWORKIN, Ronald. Levando os direitos a sério. Tradução de Nelson Boeira. São Paulo: Martins Fontes, 2002, p. 420. 
finalidades a erradicação da pobreza, objetivo bastante pretensioso se considerarmos a existência de diferenças abissais de renda ao longo da história em nosso país ${ }^{12}$.

\section{Direito como integridade}

A doutrina de Ronald Dwokin se assenta, fundamentalmente, em uma concepção inovadora de "direito como integridade". Segundo esta concepção, os juízes não possuem uma discricionariedade política para descobrir novos direitos (como, por exemplo, o direito ao aborto ou mesmo um direito ao casamento entre pessoas de mesmo sexo). Dworkin defende a ideia de que os juízes estão vinculados a determinados parâmetros tangíveis de decisão, quais sejam, os precedentes e a própria tradição legislativa que criam uma rede ordenada e lógica de princípios no curso do tempo.

Mesmo para os casos tidos como difíceis - já que para os casos rotineiros basta aplicar a lei ou o precedente -, os juízes não estariam autorizados a invadir a esfera do Poder Legislativo fazendo surgir, sponte sua, novos direitos ou mesmo fazendo derivar novos direitos a partir de direitos amplos já existentes no texto da Constituição (como, por exemplo, o direito à liberdade).

Ronald Dworkin defende que mesmo quando, ainda na década de 70, a Suprema Corte dos Estados Unidos defendeu que as mulheres tinham um direito de interromper a gravidez (aborto no primeiro trimestre de gestação) em nome da privacidade, não se pode invocar a ideia de um ativismo judicial clássico, porque esta decisão estaria em uma linha coerente de evolução da jurisprudência da Suprema Corte.

\footnotetext{
12 Veja-se, por exemplo, a informação noticiada no próprio site do STF em 6 de setembro de 2017 acerca da distribuição de verbas para o ensino fundamental através do chamado FUNDEF e que representará valores bilionários a serem desembolsados pela União em favor dos estados membros ao longo dos próximos anos: "Por maioria de votos, o Plenário do Supremo Tribunal Federal (STF), em sessão nesta quarta-feira (6), condenou a União ao pagamento de diferenças relacionadas à complementação do Fundo de Manutenção e de Desenvolvimento do Ensino Fundamental e de Valorização do Magistério (Fundef). De acordo com a decisão, o valor mínimo repassado por aluno em cada unidade da federação não pode ser inferior à média nacional apurada, e a complementação ao fundo, fixada em desacordo com a média nacional, impõe à União o dever de suplementação desses recursos. Também ficou estabelecido que os recursos recebidos retroativamente deverão ser destinados exclusivamente à educação.

O Fundef foi instituído, por meio da Lei 9.424/1996, como fundo financeiro de natureza contábil e sem personalidade jurídica, gerido pela União e composto por 15\% do ICMS e do IPI-exportação arrecadados, e do mesmo percentual para fundos de participação obrigatórios (FPE e FPM) e ressarcimento da União pela desoneração de exportações. Não atingido o piso com a aplicação apenas dos recursos estaduais e municipais, a lei determinava o aporte da União para efetuar a complementação.

No entendimento dos estados, a União descumpriu a determinação constitucional, pois efetuou a complementação com base em coeficientes regionais, e não no Valor Médio Anual por Aluno (VMAA). A União, por sua vez, alegou que os fundos seriam de natureza meramente contábil e independentes entre si, devendo ser calculados conforme critérios unicamente regionais.". REDAÇÃO. Supremo Tribunal Federal. STF condena União a pagar suplementação de verbas do Fundef entre 1998 e 2007. Notícias STF, set. 2017. Disponível em: <http://stf.jus.br/portal/cms/verNoticiaDetalhe.asp?idConteudo=354959>. Acesso em: 1 out.
} 2018. 
Ronald Dwokin defende que:

o princípio judiciário da integridade instrui os juízes a identificar direitos e deveres legais, até onde for possível, a partir do pressuposto de que foram todos criados por um único autor -a comunidade personificada -, expressando uma coerção - contém não apenas o limitado conteúdo explícito dessas decisões, mas também, num sentido mais vasto, o sistema de princípios necessários a sua justificativa. A história é importante porque esse sistema deve justificar tanto o status quanto o conteúdo dessas decisões anteriores. ${ }^{13}$

Fica patente o sincero compromisso de sua concepção do direito como integridade com um dever de honestidade intelectual e moral dos juízes de uma determinada comunidade jurídica para com os padrões históricos de moralidade. Para o autor, as áreas de atuação dos Poderes da República estavam bem demarcadas e a harmonia era desejável.

Eventuais conflitos surgem entre um Poder Judiciário federal forte (a Suprema Corte) e estados-membros que lutam para preservar sua independência, mas só raramente ocorrem no plano horizontal dentro da mesma esfera da Federação. O Congresso norte-americano goza de respeitabilidade popular e o Judiciário é visto como uma arena apenas eventual e destinada para aqueles poucos casos em que impossível estabelecer um equilíbrio entre grupos em conflito ${ }^{14}$.

Existe um vínculo indissolúvel entre as diversas gerações de juízes que se sucedem no curso da história de um país no dever de interpretação em cadeia deste grande romance histórico que é a Constituição do país. Especialmente nos países que possuem uma Constituição sintética - a qual contém algumas poucas disposições essenciais acerca dos mecanismos de tutela dos direitos individuais -, cresce a importância de fidelidade dos juízes para com a linha evolutiva de precedentes sobre o tema, bem como com os princípios que permeiam a legislação.

Não existe, dentro desta concepção do direito como integridade, uma discricionariedade política que permita criar o direito (ou criar direitos) de acordo com a vontade do juiz. Ronald Dworkin, inclusive, rebate a corrente do chamado realismo norte-americano, o qual ele considera uma forma de ceticismo jurídico, na medida em que tal grau de liberdade certamente se converteria em criticável arbítrio de juízes não eleitos diretamente pela população ${ }^{15}$.

Dworkin rejeita qualquer forma de pragmatismo puro como uma doutrina defensável para explicar as práticas jurídicas de uma determinada comunidade, porque isto significaria, na prática,

13 DWORKIN, Ronald. 0 império do Direito. Tradução de Jefferson Luiz Camargo. São Paulo: Martins Fontes, 1999, p. 273-274.

14 Já na origem do movimento constitucional dos Estados Unidos, a grande preocupação era pavimentar as vigas mestras de uma nação federativa una, mas com um poder central forte (União) e não foram poucas as vozes resistentes à criação de uma Suprema Corte da União.

${ }^{15} \mathrm{O}$ sistema de seleção e escolha dos membros da Suprema Corte dos Estados Unidos é, em linhas gerais, idêntico ao sistema brasileiro que o incorporou já na sua fase republicana, graças ao trabalho de Ruy Barbosa, com a distinção de que o Presidente da Suprema Corte (Chief Justice) é considerado um cargo fixo, enquanto que no Brasil vigora o sistema de rodízio a cada dois anos, o que certamente que contribui para sua instabilidade (e debilidade, em muitos dos casos). 
uma comunidade de direito sem direitos, ou seja, se "rejeita a existência de pretensões juridicamente tuteladas genuínas, não estratégicas" ${ }^{16}$.

O autor faz uma crítica aguda à chamada escola dos estudos jurídicos críticos (CLS - critical legal studies $)^{17}$, por exemplo, segundo a qual seria, em apertada síntese, simples perda de tempo estudar o direito, quando o correto seria estudar sociológica e antropologicamente os juízes. Neste quadrante, aquilo que o juiz tomou no café de manhã teria mais importância do que o direito propriamente dito, o qual sequer existe, não passando de uma simples justificação para o exercício arbitrário de um poder judicial indiscriminado.

A leitura da obra de Dworkin permite perceber que esta seria a maior ameaça ao direito e à própria conquista civilizatória que ele representa, ainda que esta corrente doutrinária do CLS não tenha um grande e efetivo impacto dentro do Judiciário dos Estados Unidos, como recorda Jeffrey Toobin $^{18}$.

Ronald Dworkin também se recusa a aceitar o chamado convencionalismo - ainda que sequer cite o nome de Hans Kelsen - de Herbert Hart e de outros autores que estão focados, quase que exclusivamente, na segurança jurídica, sob o argumento de que o convencionalismo não explica a nossa prática jurídica.

Ele ensina que "em um regime convencionalista, os juízes não se considerariam livres para alterar regras adotadas conforme as convenções jurídicas correntes, exatamente porque, após o exame de todos os aspectos da questão, uma regra diferente seria mais justa ou eficiente" ${ }^{19}$.

Ronald Dworkin também considera que os juízes não podem ser reféns do convencionalismo, especialmente quando se deposita no Judiciário a responsabilidade política de verificar a correspondência das leis produzidas com os princípios constitucionais (escritos ou implícitos) dos Estados Unidos ${ }^{20}$.

Os legisladores estariam adstritos aos princípios morais que condensam e expressam as grandes decisões da Nação, de maneira que os juízes têm o dever irrecusável de declarar a inconstitucionalidade de uma lei que venha a ofender claramente o padrão de moralidade coletiva

\footnotetext{
${ }^{16}$ Idem, p. 195.

17 Idem, p. 322.

${ }_{18}$ TOOBIN, Jeffrey. The nine: inside the secret world of the Supreme Court. New York: Anchor books, 2008, p. 6.

19 Idem, p. 181.

${ }^{20}$ Importante também registrar, neste momento, que existe uma forte corrente doutrinária (e judicial) nos Estados Unidos, em favor de uma interpretação e leitura dita "estrita" da Constituição norte-americana, segundo a qual os juízes da Suprema Corte estariam rigidamente adstritos ao texto escrito nos quatro cantos (four corners) da Constituição. Nesta corrente doutrinária não se aceitam os chamados direitos ou princípios implícitos na Constituição.
} 
como, por exemplo, ao negar que todos os cidadãos sejam destinatários de idêntica consideração e respeito por parte do Estado ${ }^{21}$.

Se aos membros do Congresso se revela legítimo atuar na produção de leis que tenham um viés nitidamente pragmático e comprometido, em alguma medida, com o puro utilitarismo (policies), aos juízes esta sorte de abordagem se revela como indevida pois seu compromisso, em linhas gerais, é como se uma interpretação tome em consideração os princípios (estes, por sua vez, ligados à moralidade).

Nesta concepção, os juízes não poderiam negar a concretização de um direito (individual) a partir de uma pauta política afinada com objetivos coletivos a serem alcançados, ou seja, não se pode negar judicialmente o direito da parte sob o argumento de que a decisão pode afetar o bem coletivo da comunidade.

É interesse da coletividade a tutela dos direitos individuais, o que de algum modo significa uma versão totalitária e hegemônica dos direitos individuais no confronto com os interesses coletivos $^{22}$.

Dworkin aceita que quando uma decisão política (legislativa) esteja atrelada a um bem coletivo de reconhecida importância, resta justificada a restrição ou limitação a um interesse individual.

A atividade legislativa ordinária trabalha o tempo todo com limitações e ampliações de direitos individuais e os regula de modo a torná-los harmônicos e compatíveis com os interesses maiores da coletividade, sempre que estes interesses possam ser racionalmente justificados e não apenas fruto de irrefletida discriminação.

A atividade judicial nos Estados Unidos sempre irá partir de um padrão inicial de desconfiança em relação às leis que venham a limitar os direitos individuais, exigindo do legislador níveis distintos de justificação, os quais partem da mera presença de um interesse público (muito comum na regulação de direitos ditos econômicos e de mercado) até um grau máximo (strict) para os casos que atingem as minorias ${ }^{23}$.

\footnotetext{
${ }^{21}$ No Brasil, esta concepção estaria, de alguma maneira, ligada diretamente à tutela do princípio da dignidade da pessoa humana, motivo pelo qual alguns autores, como Ingo Sarlet, por vezes trazem Ronald Dworkin em reforço de teorias que tenham como finalidade hipertrofiar o poder e a jurisdição dos juízes em detrimento dos ramos eleitos diretamente pela população. Existe, ainda, uma notável aproximação entre a distinção estabelecida por Ronald Dworkin entre princípios e políticas - traço seminal de sua obra -, que também pode ser extraída da obra de Robert Alexy, o que sugere alguma aproximação entre as duas concepções.

22 PEREZ LUNO, Antonio E. Los derechos fundamentals. Madrid: Tecnos, 1998, p. 25, também reflete acerca deste caráter dúplice dos direitos fundamentais, ao recorder que o Tribunal Constitucional da Espanha reconhece, expressamente (STC de 14 de julho de 1981 em BJC, 1981, n. 5, p. 331), que a par de serem considerados direitos subjetivos do cidadão, também se revelam como elementos essenciais de um ordenamento objetivo da comunidade nacional, que se configure como marco de uma convivência justa e pacífica, plasmada inicialmente no Estado de Direito e, mais tarde, no Estado Social e Democrático de Direito. ${ }^{23}$ Tratei destas distinções, de forma detida, no livro Direito das Minorias. São Paulo: RT, 2008.
} 
Com o notável incremento da regulação estatal nos Estados Unidos - a partir do século XX -, como nota Chereminsky ${ }^{24}$, o judiciário tem deferido ao Congresso a prerrogativa de regular estes interesses econômicos a partir da interpretação da chamada cláusula de comércio (commerce power). Este paradigma permanece até os dias atuais, sendo que a regulação econômica raramente é levada aos Tribunais.

Enquanto na Europa o critério de balanceamento e proporcionalidade é largamente difundido na comunidade jurídica e usado rotineiramente entre os juízes a partir de uma experiência inicial na Corte Constitucional da Alemanha, nos Estados Unidos a opção é em favor do critério de razoabilidade que toma em consideração a cláusula do devido processo legal (due process of $\left(a w^{25}\right)$. Para estes casos, uma lei (especialmente uma lei estadual) somente será compatível com a Constituição Federal caso exista um equilíbrio razoável entre as limitações à vida, à liberdade ou ao patrimônio e ao objetivo que se busca alcançar.

A importante distinção entre a versão substantiva e procedimental da cláusula do devido processo legal alimenta, até hoje, intensos debates na academia e na Suprema Corte dos Estados Unidos, na medida em que a corrente mais conservadora não aceita (ou aceita com grandes reservas) a ideia de uma versão substantiva da cláusula do devido processo a partir da qual seja possível fazer exsurgir direitos (derivados) de cláusulas abertas da Constituição norte-americana.

Como recorda Ronald Dworkin, ao tratar das críticas feitas por Ely à decisão da Suprema Corte no caso do aborto (Roe v. Wade), "Ely insiste em que o papel adequado do Supremo Tribunal é policiar o processo de democracia, não rever as decisões substantivas tomadas por meio destes processos" 26 .

O ativismo judicial hoje, nos Estados Unidos, estaria mais próximo da corrente doutrinária que aceita a existência de uma cláusula substantiva de devido processo legal e talvez esta seja uma das razões pelas quais parte da doutrina no Brasil busque em Ronald Dworkin uma voz autorizada em favor do ativismo. Todavia, Ronald Dworkin não aceita, de modo algum, um ativismo judicial indiscriminado que venha a servir de veículo de grandes transformações (em bloco) políticas, econômicas e sociais.

24 CHEREMINSKY, Erwin. Constitutional Law: principles and policies. Second Edition. New York: Aspen Publishers, 2002, p. 256.

25 O debate acerca da real extensão da cláusula do devido processo legal nos Estados Unidos está intrinsecamenbte conectado com a discussão acerca das virtudes e defeitos do ativismo judicial. Existe, em expressiva maioria, uma esmagadora rejeição ao ativismo judicial nos Estados Unidos, especialmente a partir das críticas feitas por John Ely na década de 70 em face das decisões proferidas pela Suprema Corte dos Estados Unidos envolvendo o aborto. A crítica ao ativismo dos juízes, todavia, já é antiga na comunidade norte-americana, sendo que o Justice Oliver Holmes já alertava para os riscos da intromissão dos juízes na esfera nitidamente política, como bem recorda Leishman (LEISHMAN, Rory. Against judicial activism: The decline of freedom and democracy in Canada. Montreal: McGill-Queen`s University Press, 2006, p. 137).

${ }^{26}$ DWORKIN, Ronald. Uma questão de princípio. São Paulo: Martins Fontes, 2005, p. 82. 
O ativismo seria justificado somente para aquelas hipóteses em que uma maioria legisla em causa própria (preferências externas, como ele designa) de maneira a alijar direitos fundamentais de determinado grupo de pessoas por conta de características que independem de sua vontade (como raça ou gênero, por exemplo).

O direito a uma igual consideração e respeito por parte do Estado é de capital importância na concepção de Ronald Dworkin e, neste sentido, ele irá buscar nos ensinamento de John Rawls ${ }^{27}$ a fundamentação para eventuais distinções que venham a existir no seio da comunidade, inclusive em relação às chamadas ações afirmativas (que defende) como, por exemplo, política de cotas em universidades públicas, desde que não estritamente raciais.

A partir desta concepção do direito como integridade, Ronald Dworkin irá desenvolver a ideia de um juiz Hércules ${ }^{28}$, dotado de capacidade de emitir juízos imparciais de moralidade política nos casos ditos difíceis - casos novos que nunca foram apreciados pelo Poder Judiciário no passado e para os quais as leis vigentes não apresentam nenhuma resposta ou que apresenta uma resposta que colide frontalmente com a moralidade vigente - sendo, por conseguinte, legitimado a decidir os casos a partir dos grandes princípios que regem a nação e que tomem em consideração um dever de tratar a todos com igual consideração e respeito ${ }^{29}$.

Segundo Dworkin,

[o] conceito central da minha argumentação será o conceito não de liberdade, mas de igualdade. (...) O governo deve tratar aqueles a quem governa com consideração, isto é, como seres humanos capazes de sofrimento e de frustração e, com respeito, isto é, como seres humanos capazes de formar concepções inteligentes sobre o modo como suas vidas devem ser vividas, e de agir de acordo com elas. ${ }^{30}$

O ativismo judicial somente se justifica para as (raras) hipóteses em que a mera invalidação da lei inconstitucional se revele manifestamente insuficiente, quando então necessária a adoção de medidas concretas de substituição por parte do Poder Judiciário, após declarada a omissão inconstitucional do Poder renitente. Ainda assim, estas decisões devem preferentemente ser precedidas de audiências públicas com efetiva participação dos representantes dos afetados, de maneira a mitigar o déficit democrático.

Para todos os demais casos em que já exista uma solução dada previamente pela legislação ou pelo texto da Constituição (casos fáceis) o papel do juiz deverá ser de deferência em favor dos

${ }^{27}$ RAWLS, John. Uma teoria da justiça. São Paulo: Martins Fontes, 2002.

28 DWORKIN, Ronald. Levando os direitos a sério. Tradução de Nelson Boeira. São Paulo: Martins Fontes, 2002, p. 141.

${ }^{29}$ A ideia de igual consideração e respeito de Dworkin toma em consideração a exigência de que o cidadão tenha as condições necessárias de participar do debate político e que também se sinta como membro integrante de uma comunidade.

30 DWORKIN, Ronald. Levando os direitos a sério. Tradução de Nelson Boeira. São Paulo: Martins Fontes, 2002, p. 419. 
ramos eleitos pela população, ainda que, por vezes, o julgador fique tentado a, em nome de uma pauta progressista, saltar sobre as prerrogativas do Congresso de emendar a Constituição.

\section{Conclusão}

O tipo de ativismo judicial praticado hoje, em larga escala, no Brasil, não encontra nenhum amparo (ainda que remoto) na vasta obra de Ronald Dworkin, porque se busca sua fonte de legitimidade em um patológico voluntarismo judicial que, historicamente, apenas serviu de fonte de legitimação para regimes totalitários.

A democracia se revela possível através de outros mecanismos senão a via judicial exclusiva - criticada por muitos como excessivamente aristocrática e apartada do contato direto com a população. O ativismo também se dá através da participação cidadã em diversas frentes, com especial ênfase na proteção dos direitos humanos ${ }^{31}$.

Para a corrente tradicional, a cláusula do devido processo possui um viés exclusivamente procedimental, no sentido de que as leis e as Constituições estaduais devem observar determinados procedimentos (ampla defesa) antes de avançar sobre a vida, a liberdade ou o patrimônio do cidadão.

A cláusula possuiria, por conseguinte, uma natureza negativa no sentido de obstar a atuação ilegal do Estado, bem como invalidar leis que venham a privar o cidadão do mais amplo direito de defesa.

Neste sentido, o direito norte-americano seria calcado na importante ideia (que vem da Inglaterra) de que todo cidadão tem o direito inalienável a um juiz imparcial e também de que não é lícito ao Congresso legislar em causa própria. Estes dois pontos constituem a espinha dorsal de qualquer ordenamento jurídico de um país minimamente civilizado.

Note-se que, nos Estados Unidos, ao contrário do Brasil, o processo de emenda à Constituição é imensamente dificultado, na medida em que por lá se exige a ratificação de boa parte dos estados-membros. Por este nobre motivo a Suprema Corte dos Estados Unidos por vezes é chamada a realizar uma leitura "ampliada" das cláusulas abertas da Constituição a partir da interpretação que se dá à cláusula do devido processo (com especial ênfase na décima quarta emenda, que trata da prerrogativa legislativa dos estados-membros e o limite no devido processo) e da cláusula que demanda igualdade de tratamento.

${ }^{31}$ KECK, Margaret; SIKKINK, Kathryn. Activists beyond borders: advocacy networks in international politics. Ithaca: Cornell University Press, 1998. 
No Brasil, de modo contrário, o processo de emenda à Constituição é bastante facilitado, de maneira que, ainda que se reconheça que o capital político do Congresso Nacional foi irremediavelmente erodido pelos recentes escândalos que assolam o país, a via rápida (fast track) do Judiciário sofre, na maior parte dos casos, de déficit democrático.

Ainda que o processo de judicialização da política não seja exclusivo do Brasil ${ }^{32}$, há que se ter o cuidado de evitar uma postura ativista que acabe por atrofiar o processo politico de debate comunitário e a próprio conceito de república, segundo o qual a discussão coletiva (seja pessoal ou via internet) leva à soluções melhores do ponto de vista da legitimidade.

O fato de que temos um fenômeno de corrupção generalizada hoje no Parlamento brasileiro deve servir de estímulo para o combate desta degeneração; nunca a derrogação total da atividade político partidária e da própria validade das eleições gerais e regulares. Os juízes não estão capacitados para governar, sob o argumento de interpretar a Constituição, na medida em que acabariam por implementar uma visão aristocrática que nem sempre corresponde à realidade do país.

Se o Poder Judiciário brasileiro buscar atender a todas as demandas políticas que forem judicializadas, haverá um notável incremento no número destas mesmas ações, criando-se verdadeira estrutura burocrática e ineficiente que, por fim, irá se mostrar incapaz de estabelecer os parâmetros mínimos de coerência e segurança jurídica no país, ainda que, em um primeiro momento este verdadeiro surto populista possa lhe render aparente sensação de que está cumprindo o seu papel histórico.

Ademais, toda e qualquer responsabilidade histórica e política do insucesso destas soluções acabará por recair na própria legitimidade dos juízes, abrindo um imenso espaço para que o Congresso traga para si a responsabilidade de legislar sobre os temas já decididos, sob o argumento de corrigir iniquidades e injustiças promovidas pelas decisões judiciais, frutos ilegítimos da politização dos juízes ${ }^{33}$.

A preocupação central do direito constitucional sempre foi com a legitimidade do processo político, sendo que os resultados concretos deste embate nem sempre representam um modelo

32 HIRSCHL, Ran. Towards juristocracy: the origins and consequences of the new constitucionalism. Cambridge: Harvard University Press, 2007, p. 169, enumera uma série de países que têm sofrido os intensos efeitos da judicialização da política, tais como Canadá, Israel, Nova Zelândia e África do Sul.

${ }^{33}$ A origem do constitucionalismo norte-americano e de uma ideia de uma Suprema Corte da União está firmemente ligada ao objetivo de se evitar a politização dos membros da Suprema Corte, os quais deveriam, segundo George Washington, ser escolhidos exclusivamente por suas qualificações técnicas. Havia uma candente preocupação de se evitar qualquer forma ou manifestação de partidarismo (grifei). Assim, GOLDSTONE, Lawrence. The Activist: John Marshall, Marbury v. Madison and the myth of judicial review. New York: Walker \& Company publishers, 2008, p. 82. 
ideal na concepção dos juízes que, ainda assim, devem resistir à tentação de sequestrar o processo político para dentro de seus gabinetes.

O fato de que Ronald Dworkin defendia uma chamada concepção substancial da democracia - segundo a qual os juízes poderiam interferir nos resultados do jogo democrático sempre que um grupo minoritário fosse arbitrariamente privado de seus direitos mínimos de participação - não sugere que esta intervenção possa ser vulgarizada para os demais casos, especialmente quando se considera o dever de imparcialidade que grava a rotina do juiz.

O "direito como integridade" de Dworkin tem um honesto compromisso com a tradição e com os melhores princípios políticos do passado, fazendo perpetuar o que de bom e legítimo se construiu; sem, contudo, renunciar ao dever histórico de eliminar a discriminação, ajudando a promover o progresso e a civilidade. Não se trata, por conseguinte, de um modelo de ruptura.

\section{Referências}

APPIO, Eduardo. Direito das Minorias. São Paulo: Revista dos Tribunais, 2008.

CHEREMINSKY, Erwin. Constitutional Law: principles and policies. Second Edition. New York: Aspen Publishers, 2002.

DICKSON, Brice. Judicial activism in common law Supreme Courts. New York: Oxford University Press, 2007.

DWORKIN, Ronald. Levando os direitos a sério. Tradução de Nelson Boeira. São Paulo: Martins Fontes, 2002.

1999. 0 império do Direito. Tradução de Jefferson Luiz Camargo. São Paulo: Martins Fontes,

. Uma questão de princípio. São Paulo: Martins Fontes, 2005.

GOLDSTONE, Lawrence. The Activist: John Marshall, Marbury v. Madison and the myth of judicial review. New York: Walker \& Company publishers, 2008.

HIRSCHL, Ran. Towards juristocracy: the origins and consequences of the new constitucionalism. Cambridge: Harvard University Press, 2007.

KECK, Margaret \& SIKKINK, Kathryn. Activists beyond borders: advocacy networks in international politics. Ithaca: Cornell University Press, 1998.

LEISHMAN, Rory. Against judicial activism: The decline of freedom and democracy in Canada. Montreal: McGill-Queen`s University Press, 2006. 
MARINONI, Luiz Guilherme. Precedentes Obrigatórios. São Paulo: Revista dos Tribunais, 2011.

PEREZ LUNO, Antonio E. Los derechos fundamentals. Madrid: Tecnos, 1998.

RAWLS, John. Uma teoria da justiça. São Paulo: Martins Fontes, 2002.

REDAÇÃO. Supremo Tribunal Federal. STF condena União a pagar suplementação de verbas do Fundef entre 1998 e 2007. Notícias STF, set. 2017. Disponível em:

<http://stf.jus.br/portal/cms/verNoticiaDetalhe.asp?idConteudo=354959>. Acesso em: 1 out. 2018.

TOOBIN, Jeffrey. The nine: inside the secret world of the Supreme Court. New York: Anchor books, 2008.

TUSHNET, Mark. Weak Courts, strong rights: judicial review and social welfare rights in comparative constitutional law. New Jersey: Princeton University Press, 2008.

\section{Minibiografia do Autor - Eduardo Fernando Appio}

Possui graduação em Direito pela Universidade Luterana do Brasil (1994), mestrado em Direito pela Universidade do Vale do Rio dos Sinos (2001) e doutorado em Direito pela Universidade Federal de Santa Catarina (2004). Pós-Doutor em Direito Constitucional pela Universidade Federal do Paraná (2007). Juiz Federal da 2a Turma Recursal dos Juizados Especiais Federais do Parana. Foi visiting scholar na Universidade de Austin, EUA (2005) e na Universidade Fordham de New York, EUA (2008). Participou do programa de Filosofia e Direito de Ronald Dworkin na New York University (NYU) em 2008.

Enviado em: 24.10.2018.

Aprovado em: 28.11.2018. 